Thorax, 1977, 32, 677-683

\title{
Nocturnal asthma and urinary adrenaline and noradrenaline excretion
}

\author{
C. A. SOUTAR ${ }^{1}$, M. CARRUTHERS ${ }^{2}$, AND C. A. C. PICKERING ${ }^{3}$ \\ From the Brompton Hospital and St. Mary's Hospital, London, UK
}

Soutar, C. A., Carruthers, M., and Pickering, C. A. C. (1977). Thorax, 32, 677-683. Nocturnal asthma and urinary adrenaline and noradrenaline excretion. Urinary adrenaline and noradrenaline excretion, heart rate, and peak expiratory flow rate have been measured every two hours for 24 hours in seven asthmatic patients suffering from nocturnal or early morning exacerbations of dyspnoea. The excretions of these catecholamines were normal or slightly raised, this being consistent with a normal response to asthma or the conditions of the test.

The expected physiological fall in catecholamine excretion occurred at night. In every patient the peak expiratory flow rate fell to its lowest values during the period of lowest catecholamine excretion, and the mean two-hourly peak expiratory flow rate for all seven patients was significantly related to the sum of the mean adrenaline and noradrenaline excretion in each preceding two-hour period $(\mathrm{P}<0.05)$.

Individually, in three patients the relationship between peak expiratory flow rate and adrenaline and noradrenaline excretion during the evening and night was so close as to be consistent with the hypothesis that changes in sympathetic tone mediated the changes in asthma. In a further three patients the relationship was present but less clear, and in one the changes in peak flow rate and catecholamine excretion were dissociated.

Studies of mean heart rate and sinus arrhythmia gap suggested that an increase in vagal tone at night might have mediated the early morning asthma in the patient in whom changes in catecholamine excretion were dissociated from change in peak flow rate.

These findings would be consistent with the view that the physiological reduction in sympathetic tone at night mediates the nocturnal and early morning exacerbation of dyspnoea in some asthmatics, although other mechanisms such as alterations in vagal tone must be important in others. Confirmation of a causal relationship requires further study.

Nocturnal and early morning dyspnoea is a frequent complaint of asthmatic subjects, and a circadian variation of airways obstruction may be detected in many asthmatics even in the absence of symptoms. The mechanism of early morning asthma is unknown and it is often difficult to treat.

It has been suggested that early morning asthma is the result of one of the biochemical circadian rhythms (Reinberg et al., 1963). A previous investigation has demonstrated that the circadian variation in plasma corticosteroids is not the main cause (Soutar et al., 1975). It is known that there is also a circadian

'Present addresses: University of Illinois Hospital, PO Box 6998, Chicago, Illinois 60680, USA

${ }^{2}$ The Maudsley Hospital, Denmark Hill, London, UK

'Wythenshawe Hospital, Manchester, UK variation in catecholamine excretion (Reinberg et al., 1969; Townshend and Smith, 1973; Carruthers et al., 1976). Drugs causing sympathetic $\beta$-blockade are known to worsen airways obstruction in asthmatics (McNeill, 1964), suggesting that endogenous sympathetic activity is important in maintaining bronchodilatation in asthmatics. The dramatic effect of sympathomimetic drugs and adrenaline in the treatment of asthma also confirms the sensitivity of asthmatic bronchi to changes in sympathetic stimulation. It is conceivable, therefore, that the physiological reduction of sympathetic activity during the night may mediate the nocturnal increase in airways obstruction occurring in many asthmatic subjects.

This study was designed to examine the temporal relationship between nocturnal asthma and changes 
in activity of the sympathetic nervous system. Sympathetic activity has been estimated by the serial measurement of urinary excretions of adrenaline and noradrenaline, which reflect indirectly adrenal secretion of these hormones and release of noradrenaline from postganglionic sympathetic nerves.

An attempt has also been made to estimate changes in vagal tone; it has been suggested by Carruthers and Taggart (1973) that not only heart rate but also sinus arrhythmia gap (the difference between the fast and slow components of sinus arrhythmia) are affected by vagal tone. Serial measurements of these variables have been made and compared with the peak expiratory flow rate.

\section{Subjects}

Seven asthmatic inpatients were studied, in whom nocturnal or morning dyspnoea was a major complaint. This study was carried out in the hope of improving control of their asthma through a more detailed knowledge of their individual needs for sympathomimetic drugs at night. Their ages ranged from 16 to 54 years. Two had positive skin prick tests. All had been taking sympathomimetic agents, but these were stopped at midnight, nine hours before the start of the study. Only patients in whom this was considered safe were included in the study.

Normal control subjects were difficult to recruit, but three ambulant normal subjects were studied, and their catecholamine excretions were compared with those in larger published series of normal subjects.

\section{Methods}

The patients rested for the study period but were allowed to sit out of bed and walk to the bathroom. Lights were dimmed at 2330 hours and patients were allowed to sleep, being wakened at two-hourly intervals for measurements to be made. Peak expiratory flow rate (the best of three attempts) was measured at two-hourly intervals for 24 hours, beginning at 0900 hours. At the same times electrocardiogram strips were obtained. Urine was collected in two-hourly aliquots, the beginnings and ends of collections coinciding with the other measurements. The urine volumes were measured and an aliquot was decanted into bottles containing sodium metabisulphite as an antioxidant, and stored at $-20^{\circ} \mathrm{C}$. Urine adrenaline and noradrenaline were measured by a semi-automated fluorimetric method. The standard deviation of the method of estimating the sum of adrenaline and noradrenaline has been shown to be $3 \%$, that of noradrenaline $5 \%$. The adrenaline concentration is obtained by calculation of the difference, and is therefore subject to cumulative errors (SD 22\%)(Carruthers et al., 1970). Mean heart rate and sinus arrhythmia gap were analysed from the electrocardiogram strips. No sympathomimetic drugs were taken during the study, except by subject 5 , who took an inhalation of salbutamol aerosol at 0400 hours because of severe coughing.

Statistical comparisons were by correlation coefficients on untransformed values of peak expiratory flow rate and urinary adrenaline and noradrenaline excretion. Comparison of heart rates and sinus arrythmia gaps was by analysis of variance on untransformed data.

\section{Results}

URINARY CATECHOLAMINE EXCRETION

The total 24-hour adrenaline and noradrenaline excretions in seven asthmatic patients and three control subjects are set out in Table 1. Most values in the asthmatic patients were within the normal range for ambulant patients found by Townshend and Smith (1973) (adrenaline 6.4-35.4 $\mu \mathrm{g}$; noradrenaline $10.4-62.2 \mu \mathrm{g}$ ) although the adrenaline excretion in two and noradrenaline excretion in three asthmatic subjects were in excess of these values.

However, the total adrenaline excretion was also higher than this range in two of our normal subjects, and noradrenaline in all three normal subjects. The mean two-hourly catecholamine excretion in the seven asthmatic subjects over 24 hours is set out in the histogram in Fig. 1 (and in Table 2). The adrenaline and noradrenaline excretions fell steadily from a peak between 1700 hours and 1900 hours to their lowest

Table 1 Total 24-hour excretion of catecholamines in seven sedentary asthmatic and three ambulant control subjects (normal range: adrenaline 6.4-35.4 $\mu \mathrm{g}$, noradrenaline $10.4-62.2 \mu \mathrm{g}$ )

\begin{tabular}{llc}
\hline & \multicolumn{2}{l}{$24-$ hour catecholamine excretion $(\mu g)$} \\
\cline { 2 - 3 } Subjects & Adrenaline & Noradrenaline \\
\hline Asthmatics & & \\
1 & $37 \cdot 5^{*}$ & $95 \cdot 7^{*}$ \\
2 & $22 \cdot 2$ & $47 \cdot 2^{*}$ \\
3 & $23 \cdot 1$ & $107 \cdot 3^{*}$ \\
4 & $57 \cdot 8^{*}$ & $45 \cdot 7$ \\
5 & $21 \cdot 5$ & $41 \cdot 7$ \\
6 & $10 \cdot 7$ & $115 \cdot 4^{*}$ \\
7 & $16 \cdot 1$ & $17 \cdot 2$ \\
Mean & $27 \cdot 0$ & $67 \cdot 2$ \\
& & \\
Controls & $92 \cdot 6^{*}$ & $115 \cdot 0^{*}$ \\
8 & $24 \cdot 0$ & $107 \cdot 5^{*}$ \\
9 & $45 \cdot 3^{*}$ & $117 \cdot 2^{*}$ \\
Mean & $54 \cdot 0$ & $113 \cdot 2$ \\
\hline
\end{tabular}

*In excess of normal values. 
values between 0300 hours and 0500 hours. By 0700 hours excretion was already rising.

Examination of values in individual asthmatic subjects confirms this pattern (Fig. 2 and Table 2).

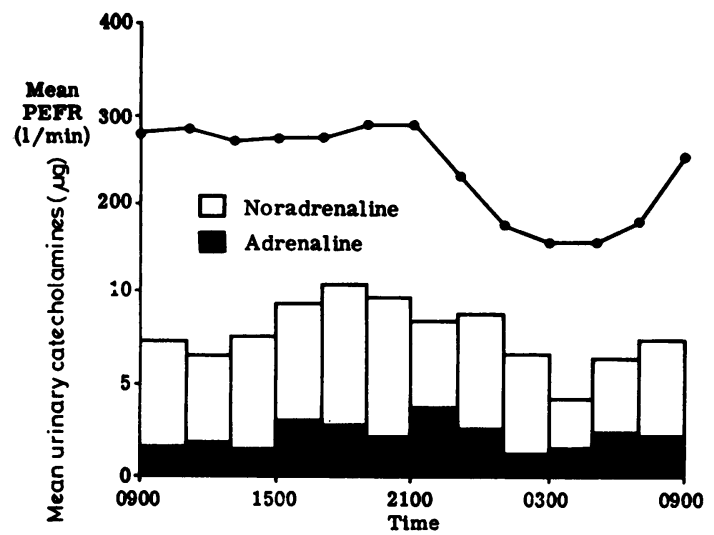

Fig. 1 Mean two-hourly catecholamine excretion and mean peak expiratory flow rate (PEFR) of seven asthmatic subjects over 24 hours. The noradrenaline value is represented by the height of the white column above the top of the black column, so that the combined height represents the sum of adrenaline and noradrenaline.
Catecholamine excretion was commonly higher in the late afternoon and evening (1500 to 2300 hours) than in the morning (subjects 1 to 5), and in all subjects excretion was low between 0300 and 0700 hours, although not necessarily lower than at any other time of day. Adrenaline and noradrenaline excretions tended to change in parallel directions, although at times the ratio between the two changed considerably.

Catecholamine excretions in the normal (and more active) subjects were higher than the asthmatic values or published normal values but again showed lower values between 0300 and 0500 hours than in the evening or daytime (Table 2).

PEAK EXPIRATORY FLOW RATE

In all the asthmatic subjects the peak expiratory flow rate fell during the night to a value lower than at any time during the day. Dyspnoea tended to be milder than that usually experienced by the patients under normal conditions. Subject 5 suffered severe coughing at 0400 hours. The mean of the peak flow readings of the seven subjects is set out in Fig. 1. Mean peak flow started to fall at $\mathbf{2 3 0 0}$ hours and was lowest at $\mathbf{0 3 0 0}$ and 0500 hours, starting to rise at $\mathbf{0 7 0 0}$ hours. After 1900 hours there was a striking correlation between the peak flow reading and the total catecholamine excretion in the two hours immediately preceding it. There was some divergence between the two measure-

Table 2 Seven asthmatic and three normal subjects: two-hourly peak expiratory flow rates (PEFR) and the sum of the urinary adrenaline and noradrenaline $(A d r+N o r)$ excreted in the two-hour period preceding each peak flow measurement

\begin{tabular}{|c|c|c|c|c|c|c|c|c|c|c|c|c|c|c|}
\hline \multirow[b]{2}{*}{ Subjects } & & \multicolumn{13}{|c|}{ Time (hours) } \\
\hline & & 0900 & 1100 & 1300 & 1500 & 1700 & 1900 & 2100 & 2300 & 0100 & 0300 & 0500 & 0700 & 0900 \\
\hline \multicolumn{15}{|l|}{ Asthmatics } \\
\hline 1 & $\begin{array}{l}\text { PEFR } \\
\text { Adr+Nor }\end{array}$ & 360 & $\begin{array}{r}380 \\
10\end{array}$ & $\begin{array}{l}380 \\
14 \cdot 3\end{array}$ & $\begin{array}{r}370 \\
9\end{array}$ & $\begin{array}{c}365 \\
12 \cdot 5\end{array}$ & $\begin{array}{r}335 \\
18\end{array}$ & $\begin{array}{l}325 \\
21 \cdot 6\end{array}$ & $\begin{array}{r}285 \\
11\end{array}$ & $\begin{array}{l}230 \\
7 \cdot 4\end{array}$ & $\begin{array}{r}220 \\
5 \cdot 7\end{array}$ & $\begin{array}{r}150 \\
1 \cdot 4\end{array}$ & $\begin{array}{r}195 \\
14\end{array}$ & $\begin{array}{l}315 \\
8 \cdot 2\end{array}$ \\
\hline 2 & $\begin{array}{l}\text { PEFR } \\
\text { Adr + Nor }\end{array}$ & 390 & $\begin{array}{l}340 \\
2 \cdot 1\end{array}$ & $\begin{array}{l}290 \\
4 \cdot 8\end{array}$ & $\begin{array}{l}335 \\
6 \cdot 2\end{array}$ & $\begin{array}{l}270 \\
7 \cdot 2\end{array}$ & $\begin{array}{l}405 \\
6 \cdot 7\end{array}$ & $\begin{array}{l}320 \\
9 \cdot 4\end{array}$ & $\begin{array}{l}220 \\
8 \cdot 1\end{array}$ & $\begin{array}{l}185 \\
7 \cdot 2\end{array}$ & $\begin{array}{l}160 \\
5 \cdot 7\end{array}$ & $\begin{array}{l}135 \\
3 \cdot 3\end{array}$ & $\begin{array}{l}230 \\
3 \cdot 6\end{array}$ & $\begin{array}{r}255 \\
5 \cdot 1\end{array}$ \\
\hline 3 & $\begin{array}{l}\text { PEFR } \\
\text { Adr + Nor }\end{array}$ & 365 & $\begin{array}{r}330 \\
14\end{array}$ & $\begin{array}{r}325 \\
4\end{array}$ & $\begin{array}{r}340 \\
9\end{array}$ & $\begin{array}{r}330 \\
6\end{array}$ & $\begin{array}{l}300 \\
14 \cdot 4\end{array}$ & $\begin{array}{l}360 \\
15 \cdot 4\end{array}$ & $\begin{array}{l}300 \\
12 \cdot 6\end{array}$ & $\begin{array}{l}260 \\
13 \cdot 5\end{array}$ & $\begin{array}{l}270 \\
10 \cdot 8\end{array}$ & $\begin{array}{l}235 \\
9 \cdot 2\end{array}$ & 270 & $\begin{array}{r}330 \\
16\end{array}$ \\
\hline 4 & $\begin{array}{l}\text { PEFR } \\
\text { Adr +Nor }\end{array}$ & 125 & $\begin{array}{l}160 \\
6 \cdot 4\end{array}$ & $\begin{array}{l}180 \\
6 \cdot 4\end{array}$ & $\begin{array}{r}145 \\
4 \cdot 2\end{array}$ & $\begin{array}{l}170 \\
17 \cdot 4\end{array}$ & $\begin{array}{r}185 \\
12\end{array}$ & $\begin{array}{l}190 \\
6.4\end{array}$ & $\begin{array}{l}155 \\
15 \cdot 6\end{array}$ & $\begin{array}{l}100 \\
13 \cdot 2\end{array}$ & $\begin{array}{l}95 \\
4 \cdot 8\end{array}$ & $\begin{array}{l}100 \\
3.6\end{array}$ & $\begin{array}{l}150 \\
7 \cdot 5\end{array}$ & $\begin{array}{r}125 \\
6\end{array}$ \\
\hline 5 & $\begin{array}{l}\text { PEFR } \\
\text { Adr + Nor }\end{array}$ & 265 & $\begin{array}{r}255 \\
3\end{array}$ & $\begin{array}{r}260 \\
2\end{array}$ & $\begin{array}{r}265 \\
6 \cdot 8\end{array}$ & $\begin{array}{r}330 \\
5\end{array}$ & $\begin{array}{l}330 \\
8 \cdot 8\end{array}$ & $\begin{array}{l}300 \\
8 \cdot 2\end{array}$ & $\begin{array}{r}220 \\
4 \cdot 3\end{array}$ & $\begin{array}{r}145 \\
5\end{array}$ & $\begin{array}{r}145 \\
6\end{array}$ & $\begin{array}{r}250 \\
3\end{array}$ & $\begin{array}{l}205 \\
5 \cdot 1\end{array}$ & $\begin{array}{r}280 \\
6\end{array}$ \\
\hline 6 & $\begin{array}{l}\text { PEFR } \\
\text { Adr + Nor }\end{array}$ & 180 & 190 & $\begin{array}{r}185 \\
14\end{array}$ & 180 & 185 & $\begin{array}{l}180 \\
12 \cdot 3\end{array}$ & $\begin{array}{l}220 \\
7 \cdot 5\end{array}$ & 6.9 & 160 & $\begin{array}{r}100 \\
13\end{array}$ & $\begin{array}{l}115 \\
7 \cdot 8\end{array}$ & $\begin{array}{l}140 \\
7 \cdot 7\end{array}$ & $\begin{array}{l}225 \\
12 \cdot 2\end{array}$ \\
\hline 7 & $\begin{array}{l}\text { PEFR } \\
\text { Adr + Nor }\end{array}$ & 240 & $\begin{array}{r}300 \\
5\end{array}$ & $\begin{array}{l}270 \\
1.4\end{array}$ & $\begin{array}{l}290 \\
5 \cdot 8\end{array}$ & $\begin{array}{r}285 \\
9.5\end{array}$ & $\begin{array}{l}290 \\
0.6\end{array}$ & $\frac{315}{1 \cdot 6}$ & $\begin{array}{l}260 \\
1 \cdot 1\end{array}$ & $\begin{array}{l}140 \\
2 \cdot 7\end{array}$ & $\begin{array}{l}150 \\
1 \cdot 6\end{array}$ & $\begin{array}{r}180 \\
0.9\end{array}$ & $\begin{array}{r}115 \\
2 \cdot 2\end{array}$ & $\begin{array}{r}295 \\
1 \cdot 5\end{array}$ \\
\hline Adr + Nor & $\begin{array}{l}\text { Mean } \\
\text { SD }\end{array}$ & & $\begin{array}{l}7 \cdot 2 \\
4 \cdot 3\end{array}$ & $\begin{array}{l}6 \cdot 7 \\
5 \cdot 4\end{array}$ & $\begin{array}{l}7 \cdot 5 \\
2 \cdot 5\end{array}$ & $\begin{array}{l}9 \cdot 7 \\
4 \cdot 3\end{array}$ & $\begin{array}{r}10 \cdot 4 \\
5 \cdot 7\end{array}$ & $\frac{10}{6 \cdot 5}$ & $\begin{array}{l}8 \cdot 5 \\
5 \cdot 0\end{array}$ & $\begin{array}{l}8 \cdot 8 \\
4 \cdot 3\end{array}$ & $\begin{array}{l}6 \cdot 8 \\
3 \cdot 8\end{array}$ & $\begin{array}{l}4 \cdot 2 \\
3 \cdot 1\end{array}$ & $\begin{array}{l}6 \cdot 5 \\
3 \cdot 8\end{array}$ & $\begin{array}{l}7 \cdot 9 \\
4 \cdot 8\end{array}$ \\
\hline \multicolumn{15}{|l|}{ Controls } \\
\hline 8 & $\begin{array}{l}\text { PEFR } \\
\text { Adr + Nor }\end{array}$ & 640 & $\begin{array}{l}660 \\
25 \cdot 7\end{array}$ & $\begin{array}{l}650 \\
25 \cdot 3\end{array}$ & $\begin{array}{l}650 \\
21 \cdot 6\end{array}$ & $\begin{array}{l}670 \\
20.5\end{array}$ & $\begin{array}{l}660 \\
23 \cdot 8\end{array}$ & $\begin{array}{l}650 \\
9 \cdot 4\end{array}$ & $\begin{array}{l}650 \\
18 \cdot 5\end{array}$ & 620 & $\begin{array}{l}655 \\
11 \cdot 4\end{array}$ & $\begin{array}{r}640 \\
7 \cdot 5\end{array}$ & 650 & $\begin{array}{r}680 \\
21\end{array}$ \\
\hline 9 & $\begin{array}{l}\text { PEFR } \\
\text { Adr + Nor }\end{array}$ & 660 & $\begin{array}{l}660 \\
9.9\end{array}$ & $\begin{array}{l}670 \\
9 \cdot 5\end{array}$ & $\begin{array}{l}660 \\
9 \cdot 6\end{array}$ & 660 & $\begin{array}{l}660 \\
9 \cdot 8\end{array}$ & $\begin{array}{l}650 \\
16.6\end{array}$ & $\begin{array}{l}650 \\
15 \cdot 4\end{array}$ & $\begin{array}{l}630 \\
16 \cdot 6\end{array}$ & 650 & $\begin{array}{l}620 \\
5 \cdot 6\end{array}$ & $\begin{array}{l}630 \\
8 \cdot 1\end{array}$ & 630 \\
\hline 10 & $\begin{array}{l}\text { PEFR } \\
\text { Adr + Nor }\end{array}$ & 630 & $\begin{array}{r}625 \\
7 \cdot 5\end{array}$ & $\begin{array}{r}625 \\
9.5\end{array}$ & $\begin{array}{r}640 \\
12\end{array}$ & $\begin{array}{l}630 \\
10 \cdot 2\end{array}$ & $\begin{array}{r}625 \\
8\end{array}$ & $\begin{array}{r}605 \\
27\end{array}$ & $\begin{array}{l}620 \\
17 \cdot 2\end{array}$ & $\begin{array}{r}630 \\
15\end{array}$ & $\begin{array}{l}610 \\
13 \cdot 3\end{array}$ & $\begin{array}{l}600 \\
6 \cdot 2\end{array}$ & $\begin{array}{l}620 \\
16 \cdot 8\end{array}$ & $\begin{array}{c}630 \\
22 \cdot 2\end{array}$ \\
\hline Adr + Nor & Mean & & $14 \cdot 4$ & $14 \cdot 8$ & $14 \cdot 4$ & $13 \cdot 2$ & $13 \cdot 9$ & $17 \cdot 7$ & $17 \cdot 0$ & $15 \cdot 2$ & $10 \cdot 5$ & $6 \cdot 4$ & $12 \cdot 2$ & $18 \cdot 3$ \\
\hline
\end{tabular}




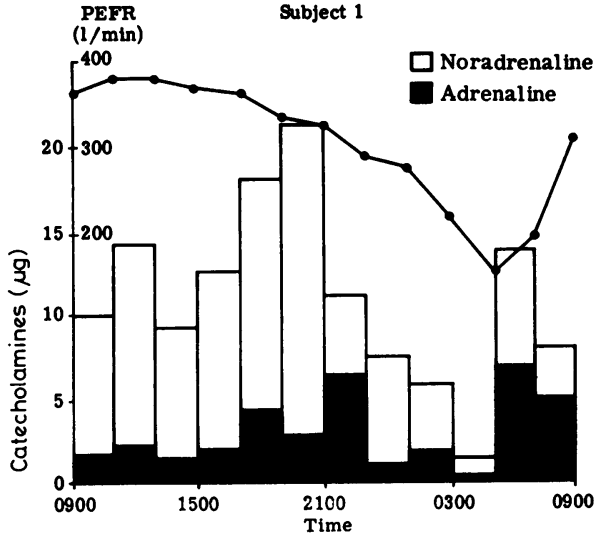

(a)

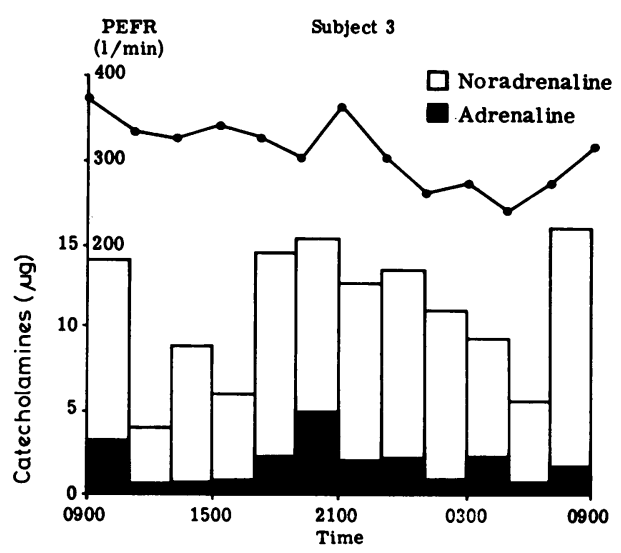

(c)

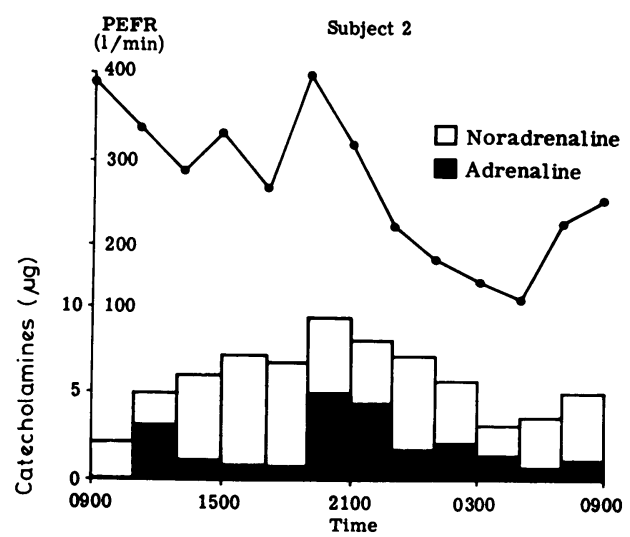

(b)

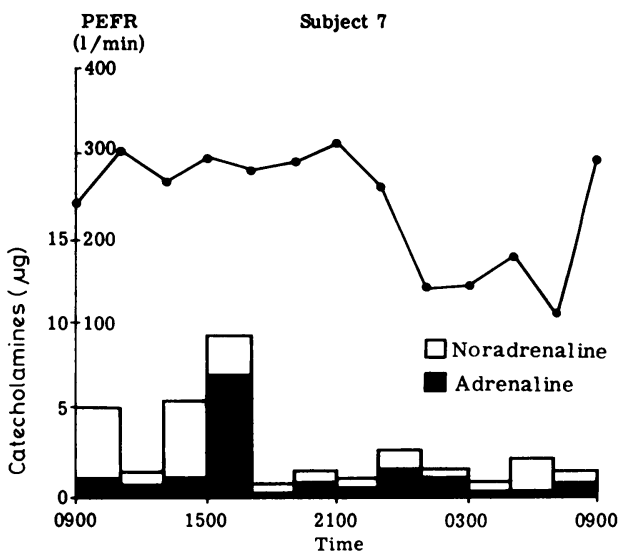

(d)

Fig. 2 (a-d) Two-hourly catecholamine excretions and peak expiratory flow rates in subjects 1, 2, 3, and 7.

ments between 0900 and 1900 hours; nevertheless the correlation between peak flow and catecholamine excretion over the whole 24-hour period is significant $(\mathrm{P}<0.05)$.

Examination of the values in individual asthmatic subjects shows that this relationship is variable. In three subjects (subjects $1,2,3$; Fig. 2 a-c) there was a striking association between the progressive fall in peak flow after 1900 hours and the progressive fall in total catecholamine excretion to a low point for both at about $\mathbf{0 5 0 0}$ hours, after which time both variables increased again. The correlation between peak flow and adrenaline and noradrenaline excretion for this 12-hour period of parallel progression was significant in each case $(\mathrm{P}<0.05)$. This relationship was not apparent during the morning and afternoon.

In three further subjects (subjects 4,5,6; Table 2) both peak flow and total catecholamine excretion were low between 0300 and 0500 hours, but a steady 음 parallel progression of the two variables was not $>$ apparent, and they were not significantly correlated. 을 Subject 5 took an inhalation of salbutamol aerosol at 0400 hours becalıse of severe coughing, and the $O r$ subsequent peak flow reading was increased, con- $N$ trasting with a low catecholamine excretion at that $\mathbb{N}^{\mathrm{W}}$ time.

In the seventh asthmatic subject (Table 2, Fig. 2d) changes in peak flow and catecholamine excretion $\stackrel{\odot}{\Phi}$ were dissociated; total catecholamine excretion fell $\stackrel{\oplus}{?}$ from day to night-time values at 1700 hours, while 0 peak flow rate did not start to fall until 2300 hours, $\bar{P}$ four hours later. The next morning peak flow rate $\mathbb{\mathbb { D }}$ rose spontaneously at 0900 hours in the absence of $\vec{D}$ any preceding increase in catecholamine excretion.

Excretions of adrenaline and noradrenaline considered separately did not show a better correlation 
with peak expiratory flow rate than total catecholamine excretion. Peak flow rates in the normal subjects were virtually constant throughout the 24 hours.

\section{HEART RATES}

Mean heart rates were significantly lower during the period 2300 to 0700 hours than the period 0900 to 2100 hours in three subjects (Table 3 , subjects $3,5,7$ ), were unchanged in three (subjects $2,4,6$ ), and increased at night in subject 1 . In the three whose heart rates were lower at night the heart and peak flow rates appeared to change in parallel, although this apparent association did not reach statistical significance.

The sinus arrhythmia gap was subject to sudden changes. Nevertheless it was significantly increased at night in subject 7 , and reduced in subject 1 . Thus, only subject 7 demonstrated both a reduced heart rate and an increased sinus arrhythmia gap during the night, both features of increased vagal activity. previous work, in which infusion of cortisol to prevent the circadian fluctuation of plasma corticosteroids failed to prevent the early morning asthma, indicated the independence of early morning asthma from the changes in plasma corticosteroids (Soutar et al., 1975).

In spite of the extensive use of sympathomimetic agents in the treatment of asthma, and the traditional use of adrenaline, remarkably little is known of catecholamine secretion in asthmatic subjects and its effect on and response to variations in asthma. An increased catecholamine response of asthmatics to exercise has been reported (Griffiths et al., 1972), and we have found that the total 24 hours' excretion of catecholamines in our asthmatic subjects was normal or slightly increased. This would be consistent with a normal response to asthma or the conditions of the test.

Circadian fluctuations of urinary catecholamines occur in normal individuals (Reinberg et al., 1969; Townshend and Smith, 1973; Carruthers et al., 1976).

Table 3 Mean heart rates and sinus arrhythmia gaps by day and by night in seven asthmatic subjects

\begin{tabular}{|c|c|c|c|c|c|c|}
\hline \multirow[b]{2}{*}{ Subjects } & \multicolumn{2}{|c|}{ Mean heart rate $(S D)$} & \multirow{2}{*}{$\begin{array}{l}\text { Significance of } \\
\text { difference }\end{array}$} & \multicolumn{2}{|c|}{ Mean $S A \operatorname{gap}(S D)$} & \multirow{2}{*}{$\begin{array}{l}\text { Significance of } \\
\text { difference }\end{array}$} \\
\hline & $0900-2100 h$ & $2300-0700 h$ & & $0900-2100 \mathrm{~h}$ & $2300-0700 h$ & \\
\hline $\begin{array}{l}1 \\
2 \\
3 \\
4 \\
5 \\
6 \\
7\end{array}$ & $\begin{array}{l}95(3 \cdot 8) \\
64(2 \cdot 0) \\
91(7 \cdot 5) \\
86(5 \cdot 0) \\
93(6 \cdot 1) \\
96(8 \cdot 9) \\
85(8 \cdot 2)\end{array}$ & $\begin{array}{r}105(5 \cdot 2) \\
67(2 \cdot 0) \\
71(2 \cdot 7) \\
82(4 \cdot 9) \\
79(6 \cdot 7) \\
91(8 \cdot 5) \\
76(6 \cdot 4)\end{array}$ & $\begin{array}{l}P<0.005 \\
\text { NS } \\
P<0.005 \\
\text { NS } \\
P<0.005 \\
\text { NS } \\
P<0.05\end{array}$ & $\begin{array}{l}29(13 \cdot 6) \\
16(2 \cdot 0) \\
17(9 \cdot 0) \\
24(10 \cdot 3) \\
26(5 \cdot 4) \\
21(16 \cdot 5) \\
19(16 \cdot 2)\end{array}$ & $\begin{array}{l}17(7 \cdot 4) \\
19(6 \cdot 8) \\
18(5 \cdot 4) \\
28(8 \cdot 9) \\
21(8.9) \\
14(1.9) \\
25(5 \cdot 8)\end{array}$ & $\begin{array}{l}P<0.05 \\
\text { NS } \\
\text { NS } \\
\text { NS } \\
\text { NS } \\
\text { NS } \\
\text { P }<0.05\end{array}$ \\
\hline
\end{tabular}

\section{Discussion} A circadian variation of airways obstruction may- period from 2300 to 0700 hours, and that this was frequently be detected in asthmatics, and in many independent of urine volume or sodium excretion. patients this manifests itself as dyspnoea during the night or early morning. This sympton may be severe and is often difficult to prevent by treatment.

Various causative mechanisms of this circadian variation have been proposed, such as the effect of the supine posture, accumulation of bronchial secretions during sleep, and exposure to house dust mite in bedding. These have been discussed previously and do not convincingly explain the phenomenon. Nor is it purely the result of a lack of treatment during sleep, for the patients in a previous study continued to suffer morning asthma in spite of taking their medication at exactly equal intervals through the 24 hours (Soutar et al., 1975).

It has been suggested that early morning asthma may be the result of one of the normal biochemical circadian rhythms; in particular, that of plasma corticosteroids (Reinberg et al., 1963), but our Our study confirms that this occurs in asthmatic subjects, the catecholamine excretion being lowest between 0100 and 0500 hours. This reduction at night was also shown by our control subjects, whose values at this time were much lower than those found during the day or early evening. The rather increased total catecholamine excretion of the control subjects is perhaps a tribute to the dynamic working habits of junior medical staff.

Our findings in seven asthmatic subjects demonstrate that the lowest urinary excretion of catecholamines occurred at night at the same time as the lowest peak expiratory flow rate, and the rise in both variables at 0500 and 0700 hours was also synchronous in all subjects but one. The mean peak flow rate for all seven subjects was correlated significantly with the mean total catecholamine excretion throughout the $\mathbf{2 4}$ hours. In three subjects the cor- 
relation between the progressive fall in peak flow and the progressive fall in catecholamine excretion after 1900 hours was striking and would at least be consistent with the hypothesis that changes in sympathetic activity were mediating the changes in the asthma. This relationship was not apparent during the earlier part of the day, indicating that other factors were influencing the asthma at that time.

In a further three subjects a progressive and parallel fall in catecholamines and peak flow was not apparent, although both values were at their lowest between 0200 and 0500 hours. This discrepancy might be the result of the limitations of comparing peak flow measured at one point in time with catecholamine excretion over a two-hour period, although it is quite possible that other factors were influencing the asthma.

In one subject it did not appear that changes in sympathetic activity could have mediated the night asthma or the morning rise in peak flow, and other factors must have been responsible. Such factors might include changes in sympathetic activity confined to the pulmonary autonomic innervation and masked by the total catecholamine excretion, or changes in vagal activity.

An attempt to estimate changes in vagal tone was made by measuring heart rate and sinus arrhythmia gap. Under the conditions of the test a fall of heart rate at night was seen in only three subjects, and in these, changes in heart and peak flow rates tended to occur in parallel. Changes in both these variables could as well be the result of changes in sympathetic as in vagal activity. The heart rates were generally faster at night than those recently reported in normal subjects (Clarke et al., 1976), although our patients were being disturbed every two hours.

The sinus arrhythmia gap was increased at night in only one subject, who also had a relative bradycardia at night. This patient had the lowest nocturnal catecholamine excretion of all, and the relative bradycardia at night may have been the result of reduced sympathetic activity rather than increased vagal activity. However, it has been suggested that widening of the sinus arrhythmia gap may be the result of increased vagal tone even in the presence of increased sympathetic activity (Carruthers and Taggart, 1973). If this is true, then vagal tone may have been increased at night in this patient, and since it was clear in this particular subject that changes in catecholamine secretion were not the cause of the changes in peak expiratory flow rate, it is conceivable that the night asthma was vagally mediated.

Catecholamine secretion is increased by physical activity (Vendsalu, 1960), and the circadian variation may be over-ridden by physical exertion during the night (Townshend and Smith, 1973). The fall in catecholamine secretion at night may be at least partly the result of reduction of physical activity at night, although a circadian rhythm of catecholamine secretion is known to occur even in subjects confined to bed throughout the day (Reinberg et al., 1969). It is conceivable that subjecting an asthmatic to the relatively sedentary and regular routine of a hospital inpatient may further reduce sympathetic activity at night and thus exacerbate the morning asthma.

If early morning asthma is the result of low sympathetic activity during sleep, this implies a need for larger therapeutic doses of sympathomimetic agents at night than during the day if nocturnal symptoms are troublesome. Personal clinical experience with sympathetic $\beta$-stimulants in slow-release oral preparations given at night has suggested that a proportion of patients with early morning asthma benefit from these preparations. The more severely affected patients are resistant to treatment with conventional doses, although the early morning asthma usually responds rapidly to inhalation of sympathomimetic aerosol. The sum of the endogenous sympathetic activity and the exogenous sympathetic stimulation by drugs may be insufficient to maintain bronchodilatation when the endogenous sympathetic activity is at its lowest during the night. Similarly, $\beta$-blockers, especially those with no intrinsic sympathomimetic activity, may inhibit bronchodilatation and induce asthma in susceptible subjects (Imhof, 1974).

It is possible that changes in sympathetic activity mediate changes in asthma during the day as well as night. This study failed to show any clear relationship between catecholamine excretion and peak expiratory flow rate during the daytime, but changes in sympathetic activity may be relevant to the phenomenon of exercise-induced asthma. It has been shown that plasma concentrations of catecholamines rise in response to exercise and fall sharply within a few minutes of cessation (Vendsalu, 1960). This change in sympathetic activity might contribute to the severity of exercise-induced asthma, which characteristically becomes severe shortly after cessation of exercise and is more effectively prevented by sympathomimetics than by any other drug (Godfrey, 1975).

In conclusion, nocturnal and early morning exacerbations of dyspnoea in these asthmatics were synchronous with a fall in urinary catecholamine excretion, and it is possible that in some subjects the reduction in sympathetic activity at night mediates increased airways obstruction. Confirmation of a causal relationship requires further study.

We thank Professor M. Turner-Warwick, Dr. H. Nicholson, and Dr. T. J. H. Clark for permission to $\varrho$ study their patients, the sisters and nurses of Blunt Ward for a tremendous amount of practical help, and 
Dr. E. Dunbar for being a normal subject. We also thank Mrs. S. Gleave and Miss J. Foster for secretarial assistance.

The biochemical estimations were performed by Miss Heather Kerr and Mr. Russel Rose under grants from CIBA Laboratories and the British Heart Foundation.

\section{References}

Carruthers, M., Arguelles, A. E., and Mosovich, A. (1976). Man in transit: biochemical and physiological changes during intercontinental flights. Lancet, 1, 977-981.

Carruthers, M., and Taggart, P. (1973). Vagotonicity of violence: biochemical and cardiac responses to violent films and television programmes. British Medical Journal, 3, 384-389.

Carruthers, M., Taggart, P., Conway, N., Bates, D., and Somerville W. (1970). Validity of plasmacatecholamine estimations. Lancet, 2, 62-67.

Clarke, J. M., Hamer, J., Shelton, J. R., Taylor, S., and Venning, G. R. (1976). The rhythm of the normal human heart. Lancet, 2, 508-512.

Godfrey, S. (1975). Exercise-induced asthma: clinical, physiological and therapeutic implications. Journal of Allergy and Clinical Immunology, 56, 1-17.

Griffiths, J., Leung, F. Y., Grzybowski, S., and ChanYeung, M. M. W. (1972). Sequential estimation of plasma catecholamines in exercise-induced asthma. Chest, 62, 527-533.
Imhof, P. R. (1974). In Beta-blockers; Present Status and Future Prospects, edited by W. Schweizer, p. 43. H. Huber, Berne.

McNeill, R. S. (1964). Effect of a $\beta$-adrenergic-blocking agent, Propanolol, on asthmatics (Letter). Lancet, 2, 1101-1102.

Reinberg, A., Ghata, J., and Sidi, E. (1963). Nocturnal asthma attacks: their relationship to the circadian adrenal cycle. Journal of Allergy, 34, 323-330.

Reinberg, A., Halberg, F., Ghata, J., Gervais, P., Abulker C., Dupont, J., and Gaudeau, C. (1969). Rythme circadien de diverses fonctions physiologiques de l'homme adulte sain, actif et au repos (pouls, pression artérielle, excrétions urinaires des 17-OHCS, des catécholamines et du potassium). Journal de Physiologie, 61, Supplement 2, 383.

Soutar, C. A., Costello, J., Ijaduola, O., and TurnerWarwick, M. (1975). Nocturnal and morning asthma: relationship to plasma corticosteroids and response to cortisol infusion. Thorax, 30, 436-440.

Townshend, M. M., and Smith, A. J. (1973). Factors influencing the urinary excretion of free catecholamines in man. Clinical Science, 41, 253-265.

Vendsalu, A. (1960). Plasma concentrations of adrenaline and noradrenaline during muscular work. Acta Physiologica Scandinavica, 49, Supplement 173, 5769.

Requests for reprints to: Dr. C. A. Soutar, University of Illinois Hospital, PO Box 6998, Chicago, Illinois, 60680 , USA. 